\title{
A Discussion on the Importance of Functionality in Passive Voice with Discourse and Meaning
}

\author{
Jihye Lee \\ Hannam University, 70 Hannamro, Daedeok-Gu Daejeon 34430, Korea \\ yjh2488@naver.com
}

\begin{abstract}
A core of language acquisition is to communicate properly between speaker and listener and send a message correctly. To do so, we should know discourse function and pragmatic language process. In this discussion, to learn passive voice in accordance with the discourse function and context, we analyze what passive voice is and what connection lies between passive voice and discourse and pragmatic function and meaning. There are many principles about it but in this study, there are three principles here. First is End-weighing. As we usually have an interest in and can easily accept the 'new information' it is recommended for us to use passive form. Second, each element such as subject or object in the sentence has a hierarchy. Therefore, it is necessary to understand their hierarchy in the sentence that is expressed with passive voice. Depending on the speaker's intention, the agent of sympathy is different. Lastly, there is an argument that topic is totally different from subject. Syntactic Subject in English has a dual function. Its primary function is to encode thematic information.
\end{abstract}

Keywords: Passive voice, Discourse function, Pragmatic context, End-focus, Empathy, Topics.

\section{Introduction}

Generally passive voice is a grammatical form that it would not change its meaning but change its agent and subject. When a person is doing something it is called Active. When the subject is what the action is directed at we can use passive verb. Passive voice is usually used in an academic journal or professional context. If we get a certain level of education we are expected to make use of passive voice proficiently. Curme [1] said that it is passive voice that is the most preferred expression in English. Also, he claimed that it plays an important role in a sentence by making it much more concise and diverse. Freeman [2] admitted that it is very demanding and time consuming for L2 learners to acquire passive voice. However, L2 learners had better learn the form and function of passive voice. According to these arguments the form and function of passive voice should be learned carefully. Also, it is important to teach it accurately. Due to difficulty of the concept and form of passive usage, L2 learners seem to be reluctant to use passive voice although now we spend much time and effort teaching it. This is because L2 learners' mother tongue, Korean has a lexical passive expression. Korean is the language of which dependence lies on a scene. Usually it seems that a voice of the Korean language is ambiguous. The things which are limited compared to other

Article history:

Received (June 24, 2019), Review Result (August 15, 2019), Accepted (September 30, 2019) 
languages that are filled with scenes in Korean. Korean is not a syntactically advanced language, but rather a pragmatically developed language [3]. Especially in traditional grammar teaching method, L2 learners have just turned an active voice into a passive voice, not considering the context where passive voice is used. This simple drill exercise deprives L2 learners of the chance to know when and why we should use a passive voice properly. Curme [1] mentioned that the traditional teaching method causes L2 learner to misunderstand that passive is another form of active but it's not true. A core of language acquisition is to communicate properly between speaker and listener and send a message correctly. To do so, we should know discourse function and pragmatic language process. In this discussion, to learn passive voice in accordance with the discourse function and context, we analyze what passive voice is and what connection lies between passive voice and discourse and pragmatic function and meaning.

\section{Passive voice}

There are many classifications about passive voice. Let me introduce some of them. Jespersen [4] explained the usage of passive voice in respect of functional aspect as following.

(1) The subject of the active voice is unclear or cannot be easily identified

a) The city is well supplied with water.

b) The murderer was caught yesterday.

(2) The subject in the context is too obvious to reveal.

a) His memory of this event was lost beyond recovery.

(3) Do not want to expose the subject, and do want to avoid repeating the subject 'I'

a) Enough has been said. (=I have said enough)

b) This matter will be more fully dealt with in a later chapter.

(4) To emphasize the subject in the passive voice.

a) The house was struck by lightning.

b) His son was run over by a bus.

As above,[4] Jespersen addressed that passive voice is used frequently when the subject is emphasized in the context, so called Topicalization. Let's look at another one.

Robert [5] said in academic journal, it is said that the writer uses passive voice when he or she doesn't want to reveal himself or herself.

a) It was felt that the theory was not enough to solve such a problem.

To avoid self-centered expression such as 'I feel-', it is recommended to use the passive voice like 'It was felt that-'. That is passive phrase is more useful for technical books whose purpose is to communicate facts and information without the writer's personal opinion.

Quirk Et al. [6] explained that when we usually employ passive voice as following.

(1) They do not know the identity of the agent of the action.

(2) They want to avoid identifying the agent because they do not want to assign or accept responsibility.

(3) They feel that there is a reason for mention of the agent because the identification is unimportant or obvious from the context.

(4) To put emphasis on the agent of the action.

(5) To avoid what would otherwise be a long active subject.

(6) To retain the same subject in later part of the sentence. 


\section{Discourse and pragmatic meaning of passive voice}

\subsection{The principle of end-weighing}

Linguists who address language function and meaning are interested in functionality of a language contrary to focusing on form. A passive form which is viewed by the functionalism is not chosen randomly, though two verbs forms can be used in one premise, and as they say there is such a reason why a certain form is chosen. Actually, it is said that a successful discourse process is to communicate the contents that a speaker wants to say to a listener timely and properly. In this respect, from now on, this analysis is going to show some affirmative interrelation between passive form and discourse and aspect of function.

a) What did your brother do?

b) He was doing his project in his room.

c) (?) The project was being done in his room by him.

In the above sentence, we simply realize that the subject of the sentence is 'your brother'. In the case of (b) we know what the agent is doing so we assign a subject as 'He'. However, in the case of (c) there is an entirely different subject. It does not violate grammar rules but violate a whole context of the sentence. That is because another subject that is not intended by a speaker exists in the sentence. The sentence of (c) cannot be included in the principle of discourse. It is related to the Information Flow. In terms of Information Flow principle, the contents which a speaker or writer wants to communicate are classified with two things, one is the information that a listener or a reader has already known, the other is the information which they don't know at all. The former is 'given information' and the latter is 'new information'. We usually regard new information as more important and valuable. However, an ideal communication is consistent with given information and new information contents harmoniously [7]. There is a tendency that we called it End-Focus or End-Weigh, which new information is located in the end of the sentence. [8] Quirk explained this principle, saying as follow.

"As a part of the principle of end-weigh in English, there is a feeling that the predicate of a clause should where possible be longer than the subject: thus, a principle of structural compensation comes into force."

\subsection{The principle of empathy}

[9] Kuno associated passive form with a principle of discourse. According to his claim, a speaker tends to put the most important element into a dominant position that is a subject in order to see it as a whole context. He called it 'Empathy'. In terms of the principle, passive voice makes an object in an active voice be a superficial subject so as to be a target of empathy. [10] Kuno's Empathy principle is explained as follow.

(1) Surface structure Empathy Hierarchy: It is easiest for the speaker to empathize with the referent of the subject than with the referents of other NPs in the sentence: E(subject) > E(other NP). [10]

(2) Topic Empathy Hierarchy: Given an event or state that involves A and B such that A is conferential with the topic of the present discourse and $\mathrm{B}$ is not, it is easier for the speaker to empathize with A than with B: E(discourse-topic) $\geq \mathrm{E}$ (nontopic).

(3) Word order Empathy Hierarchy: It is easier for the speaker to empathize with the referent of a left-hand NP in a coordinate structure than with that of a right-hand NP: E(Lefthand NP) > E(Right-hand NP) [10]. 
(4) Syntactic Prominence Principle: Give syntactic prominence to a person/ an object that you are empathizing with[10].

a) I saw John and a student walking together yesterday.

b) (?) I saw a student and John walking together yesterday [10].

According to Kino's Anaphoricity Hierarchy, the sentence (b) is not accepted as normal. Concerning with empathy, a first person pronoun is to be a first more than second or third person pronoun. If 'a student' is preceded before 'John' it indeed violates the principle.

\subsection{Topic and subject}

[11] Li \& Thompson drew very fine distinctions between topic and subject.

"The topic is a discourse notion, whereas the subject is to a great extent a sentence-internal notion. The former can be understood best in terms of the discourse and extra-sentential consideration; the latter in terms of its functions within the sentence structure."

They said that topic should be understood as a contextual discourse element rather than syntactical structure element. So, what is the definition of a subject? [12] Mac Whinney claimed a subject is a starter of the sentence and has four meaning functions.

(1) Attention Focus

(2) Perspective

(3) Agent

(4) Givenness

"Syntactic Subject in English has a dual function. Its primary function is to encode thematic information. Its secondary function is to encode the semantic role agent. What this means is that when several NPs(arguments) compete for the subject relation, the one representing the most thematic information will win. If no NP can be established as the most thematic, then the Subject will take the Agent" [13].

Taken together, a subject comes under a topic and a topic like a subject gets a focus. As a topic is a subjective thing centered on a speaker or writer and it is also the speaker who decides the topic of a sentence, it is natural for shared information to be front of the sentence. For this reason the subject of a passive form has perspective and governess and it is usual to use a topic emphatic sentence with a passive form. Let me tell you about Definiteness which is one of the features in Topic.

Definitive NP has a high topicalization. But not all definitive NP becomes a topic. Even indefinite NP also becomes a topic when a listener has already realized the background or context which a speaker intends to say.

We often violate some traffic rules this is why certain measures should be carried out.

Above the sentence, we get to know that 'certain measures' is a topic of the sentence though there isn't any clue about the measures. This is because we simply recognize what certain measures are. Likewise indefinite NP plays a role in topic, bringing us authentic effect on the sentence.

\section{Discourse aspect of the passive in the text}

Language is a communication tool between speaker and listener. To achieve effective communication, we should learn what the discourse is, what situation we are in, which context we should choose and what the pragmatic elements are in this communication.

When we consider the basic unit of the discourse as a sentence there is a topic and focusing on the functional elements of the discourse. The selection standard for topics and focusing are the purpose of a statement, discourse circumstance and the intention of the speaker. The 
selection of the topic is determined by the purpose or direction of the discourse. The topic serves to set a proper range of the following descriptions. The most common feature of the topic element is that it is located at the front of a sentence and there are other features: constraints to facilitate identification of identity, given information. Most forms are in forms of nouns at the in front of a sentence. The reason is that the speaker informs the listener in advance of what to provide information about so that the listener is prepared to accept that information.

English tends to match the subject with the topic. The topic is often used as the speaker's discourse strategy, serving as the starting point of the message and as an element that gives the speaker special meaning. When grammatical and informational sequence does not match, structural and semantic topics may also appear to match the subject and the topic. The most frequently chosen way of matching the subject with the topic is passive voice form. In other words, if in a given situation the subject matter is not the agent but the object of the act or the action, the subject that the speaker tends to intend does not agree with the topic. For this reason we usually match the subject with the topic by defining the agent and the object using the passive form. Passive voice not only serves to convert subject matter into agent matter but also weakens non-topic elements. The following text is an example of the use of passive voice when attempting to select a highly subjective element.

Reusing is the easiest and cheapest kind of recycling. It saves a lot of energy, materials and money. Glass containers are easy to reuse. In Britain, the milkman brings bottles of milk to house and collects the empty milk bottles. The bottles are cleaned and refilled. Every milk bottle can be reused at least thirty times [14].

The above text is an excerpt of Korean first-year high school English textbooks on recycling bottles. The subject of this text is 'bottles'. To maintain the consistency of the subject, the underlined parts were created using the passive form. The word 'bottle' was presented before the passive form was used, so it is a given information. Furthermore, another determinative is also used such as 'the' and 'every milk'

Her final report was e-mailed to Mr. Beck. She hopes that her report will be chosen as one of the best reports. Maybe her report will be read by thousands of people [15].

The subject is 'report' and we realize that the text uses passive voice to maintain the consistency of the subject matter by using given information. Also, to keep the rules of discourse it uses the passive voice like 'will be read'.

So why should we value the discourse in the passive voice? According to [16] Jung dongbin a discourse analysis is a process of analyzing a discourse using the theoretical principles and elemental concepts unique to linguistics, namely, regularity suitability. The first thing of analysis is to separate units of discourse, categories of discourse and aggregate of discourse. The second is to formulate this linguistic categorized rule. In other words, discourse analysis of how language is being used according to its context by looking at the relationship between language structure and its context. This is a balance between form and function. In order to uphold the principle of this discourse, we need to recognize and understand the use of passive voice.

\section{Conclusion}

As we have discussed and analyzed passive voice so far we can conclude as follow. This study is to aim at discussing passive voice in terms of discourse and meaning aspect. Because passive voice itself can be used in a discourse context in many ways. Also Language is examined by a social and psychological aspect as well as by structural and syntactical aspect. 
We have preferred using passive form when we want to represent unanimated thing or a certain circumstance as a subject. However, we have overlooked a discourse aspect that passive voice should have. For meaningful and authentic use of verb form especially passive voice, we have to realize the value about its discourse and function. This discussion reviews and analyzes many prior theories which show passive form accordance with discourse and pragmatic meaning. There are many principles about it but in this study, there are three principles here. First is End-weighing. As we usually have an interest in and can easily accept the 'new information' it is recommended for us to us passive form. Second, each element such as subject or object in the sentence has a hierarchy. Therefore, it is necessary to understand their hierarchy in the sentence that is expressed with passive voice. Depending on the speaker's intention, the agent of sympathy is different. Lastly, there is an argument that topic is totally different from subject. Syntactic Subject in English has a dual function. Its primary function is to encode thematic information. Its secondary function is to encode the semantic role agent. Whenever we make a sentence or have a conversation, if we have in mind these principles successful communication is achieved and the intention that a speaker wants to say is well expressed.

\section{References}

[1] G. O, Curme, "Parts of speech and accidence," New York: Health and Company

[2] D. Larsen Freeman, "On the teaching and learning of Grammar: Challenging the Myths," MAT Program, School for International Training, Brattleboro, Vermont

[3] Kim Jong Taek, "Korean pragmatics," H.S Publish

[4] O. Jespersen, "A modern English grammar III," George Allen and Unwin, London

[5] P. Robert, "Understanding grammar," New York: Haper \& Row

[6] R. Quirk and S. Green baum, “A student's grammar of the English language,” London: Longman Group UK Ltd

[7] Park Keun Woo, "English grammar of pragmatics," H.S Press

[8] R. Quirk, “A grammar of contemporary English,” New York: Seminar Press Inc

[9] S. Kuno, "Subject, theme and the speaker's empathy," In Li, C (Eds,), Subject and Topic, New York: Academic Press

[10] S. Kuno, "Functional syntax," Chicago, London: The university of Chicago Press

[11] C, N. Li, \& S. A. Thompson. "Subject and topic: A new typology of language," Charles N. Li (ED.), Subject and Topic, New York: Academic Press

[12] B. Mac Whinney, "Starting point," Language, vol.53, no.1

[13] R. S, Tomlin, "On the interaction of syntactic subject," Thematic Information, and Agent in English

[14] Lee hongsoo, "English for everyone," Korean high school textbook, Lesson 11, (2002)

[15] Im byengbin, "English for everyone," Korean high school textbook, Lesson 1, (2002)

[16] Jung dongbin, "Modern English linguistic," H.S Press 